\title{
Cutaneous Effects of Exposure to Polybrominated Biphenyls (PBBs): The Michigan PBB Incident
}

\author{
Joseph J. Chanda, ${ }^{*}$ Henry A. Anderson, $\dagger$ Roman W. Glamb, \\ Diane L. Lomatch, ${ }^{*}$ Mary S. Wolff, $\dagger$ John J. Voorhees, ${ }^{*}$ and \\ IRVING J. SELIKOFF'
}

\begin{abstract}
*University of Michigan, Department of Dermatology. Ann Arbor. Michigan 48109, and †Mount Sinai School of Medicine of The Citv University of New York. Environmental Sciences Laboratory, New York, New York 10029
\end{abstract}

Received September 17, 1981

In 1973 an environmental accident occurred in northern Michigan in which $1000-2000$ pounds of the toxic fire retardant polybrominated biphenyl (PBB) was added to the livestock food supply of much of northern Michigan. PBB is highly lipophilic, poorly metabolized, and biocumulative. It subsequently entered the human food chain of the entire state of Michigan. Health effects were noted in contaminated animals and among exposed farmers some months after the contamination: these often included cutaneous problems. Three years later a multidisciplinary study of the farming population was undertaken. Detected cutaneous abnormalities included halogen acne, hair loss, skin redness, skin peeling, and scaling, itching, increased sweating, and increased growth of fingernails and toenails. The mechanisms underlying these effects are unknown. PBBs appear to be etiologically implicated for significant cutaneous toxicity.

\section{INTRODUCTION}

During the late spring of 1973 , an environmental accident occurred in the state of Michigan with far-reaching medical, economical, political, and legal implications (1). As a result of a labeling error, approximately $1000-2000$ pounds of the toxic fire retardant polybrominated biphenyl (PBB; trade name Firemaster) was substituted for the nontoxic feed supplement magnesium oxide (trade name Nutrimaster) and inadvertently added to the livestock food supply of much of northern Michigan. During the summer of 1973, adverse health effects (weight loss, lethargy, decreased milk production, alopecia, poor resistance to infection, infertility, and abortion) began to appear in animals that consumed the contaminated food (2). A few months later farmers and area residents whose food supply derived primarily from these animals also began to note adverse symptoms (3). The labeling error was not discovered and PBB was not isolated and identified as a probable cause of the abnormalities until almost a year after the substitution error occurred. During that period of time contaminated animals and their produce entered the human food supply of the state of Michigan. The result was the contamination of much of such food with polybrominated biphenyls.

Polybrominated biphenyls are polyhalogenated hydrocarbons which are structurally similar to polychlorinated biphenyls (PCB). PCBs have been manufactured for over $\mathbf{4 0}$ years, have multiple industrial uses, and are well-known environmen- 
tal contaminants. PBBs have only recently been manufactured, were used as a plastics flame retardant, and had never been previously implicated as environmental contaminants. Both substances are water insoluble, fat soluble, and extremely nondegradable (1). They readily pass from substance to substance in the food chain, and are therefore potentially biocumulative (1). The PBB involved in the Michigan incident was Firemaster FF-1 manufactured by the Michigan Chemical Corporation. It was a mixture of polybrominated biphenyls comprising $75 \%$ bromine by weight. The two major components of the mixture are hexabromobiphenyl (BP-6) and octabromobiphenyl (BP-8) (1, 4). Trace amounts of brominated naphthalenes were also identified in the mixture (1).

Prior to the Michigan PBB incident, there was no available information about the human toxicity of PBBs and relatively little about their toxicity to animals (5-8). There was, however, much information about the toxicity of PCBs. Various animal studies had shown these agents to be teratogenic, carcinogenic, immunosuppressive, embryolethal, acnegenic, hepatotoxic, and to cause chronic systemic toxicity characterized by lassitude, anorexia, and irritability (9-13). In addition, there was a documented episode of human PCB poisoning which occurred in Japan in 1968 (14). Approximately 1000 individuals consumed rice oil which had been heavily contaminated with PCBs, with adverse health effects found in some contaminated individuals a few months later. These health effects are outlined in Table 1. It is of interest to note that the Yusho PCBs have recently been found to have been significantly contaminated with extraordinarily toxic chlorinated dibenzofurans, which may account for much of the toxicity described (15).

Following the identification of PBB in animal feed in Michigan and its implication as a toxic agent (2), a medical study of involved individuals was undertaken. This included field examinations of more than 1000 exposed individuals in Michigan in November 1976, and, in the spring of 1977 . over 200 nonexposed controls in a neighboring dairy farming area in Wisconsin (16).

On the basis of toxic effects observed in PBB-contaminated animals, symptoms and signs which had developed in individuals in the Yusho PCB incident, and observations in PCB animal toxicity studies, the following hypothesis regarding the cutaneous toxicity of PBBs was formulated: Human exposure to PBBs may result in the following cutaneous problems: (1) acne (halogen or bromacne); (2) irritant or allergic contact dermatitis; (3) pigmentary changes; (4) alopecia; (5) nail dystrophy; (6) folliculitis; and (7) increased sweating. This report will describe cutaneous abnormalities observed in this study.

\section{MATERIALS AND METHODS}

Selection of subjects. The study focused on the examination of individuals who we had reason to believe had been significantly exposed to polybrominated biphenyls. Significant exposure was defined as being directly involved in the manufacturing and processing of PBBs, or residing on a farm where livestock had consumed PBB-contaminated feed ("quarantined farms"). A list of these farms was provided by the Michigan Department of Agriculture. A stratified sample of farm families residing on such farms was then randomly invited to participate in 
TABLE 1

Toxicity of Chlorinated Biphenyls: Subjective Symptoms Complained of By Yusho Patients

\begin{tabular}{lcc}
\hline \multicolumn{1}{c}{ Symptom } & $\begin{array}{c}\text { Male } \\
(\%)\end{array}$ & $\begin{array}{c}\text { Female } \\
(\%)\end{array}$ \\
\hline Dark brown pigmentation of nails & 83.1 & 75.0 \\
Distinction of hair follicles & 64.0 & 56.0 \\
Increased sweating at palms & 50.6 & 55.0 \\
Acnelike skin eruptions & 87.6 & 82.0 \\
Red plaques on limbs & 20.2 & 16.0 \\
Itching & 42.7 & 52.0 \\
Pigmentation of skin & 75.3 & 72.0 \\
Swelling of limbs & 20.2 & 41.0 \\
Stiffened sole and palm & 24.7 & 29.0 \\
Pigmented mucous membrane & 56.2 & 47.0 \\
Increased eye discharge & 88.8 & 83.0 \\
Hyperaemia of conjunctiva & 70.8 & 71.0 \\
Transient visual disturbance & 56.2 & 55.0 \\
Jaundice & 11.2 & 11.0 \\
Swelling of upper eyelids & 71.9 & 74.0 \\
Feeling of weakness & 58.4 & 52.0 \\
Numbness in limbs & 32.6 & 39.0 \\
Fever & 16.9 & 19.0 \\
Hearing difficulties & 18.0 & 19.0 \\
Spasm of limbs & 7.0 & 8.0 \\
Headache & 30.3 & 39.0 \\
Vomiting & 23.6 & 28.0 \\
Diarrhea & 19.1 & 17.0 \\
\hline
\end{tabular}

"Eighty-nine male and one hundred female patients diagnosed before October 31 , 1968, were examined.

${ }^{b}$ From a report of "Yusho: A poisoning caused by rice oil contaminated with chlorobiphenyls" $(8)$.

the clinical field study. Approximately 55\% of the individuals so invited agreed to participate and were examined. In addition, individuals considered to have been less heavily exposed ("nonquarantined farms") were similarly selected, as were others. Details of the study groups have been reported (16).

Definition of study group and controls. Members of the study group comprised three separate classes: (1) residents of quarantined farms; (2) residents of nonquarantined farms; and (3) Michigan Chemical Company workers. Residents of quarantined farms were defined as those individuals who lived on farms with livestock that had been fed PBB-contaminated feed and where (random) serum samples from these animals studied by the Michigan Department of Agriculture had shown PBB levels of $0.3 \mathrm{ppm}$ or greater. Residents of nonquarantined farms were defined as those individuals who lived on farms with livestock where serum samples from these animals had shown PBB levels of less than $0.3 \mathrm{ppm}$ or levels that were nondetectable. The $0.3 \mathrm{ppm}$ level ("action level") had been utilized by the Michigan Department of Agriculture to categorize "quarantined" versus "nonquarantined" farms. It is recognized that this parameter has limited cogency in attempts to quantitate human exposure. 
TABLE 2

Serum PBB Levels among Individuals Exposed to PBB in MichIgan AND AMONG DaIRY FARMERS IN WiSCONSIN

\begin{tabular}{|c|c|c|c|c|c|c|}
\hline \multirow[b]{2}{*}{ Group } & \multirow{2}{*}{$\begin{array}{l}\text { Number } \\
(N)\end{array}$} & \multirow{2}{*}{$\begin{array}{l}\text { Sex } \\
(\mathrm{m} / \mathrm{f})\end{array}$} & \multirow{2}{*}{$\begin{array}{c}\text { Group age } \\
\text { distribution } \\
\text { (years) }\end{array}$} & \multirow[b]{2}{*}{$(N)$} & \multicolumn{2}{|c|}{ Serum PBB $^{\prime 2}$} \\
\hline & & & & & Mean & Range \\
\hline $\begin{array}{l}\text { Quarantined farm } \\
\text { exposure }\end{array}$ & 485 & $243 / 242$ & $\begin{array}{l}0-5 \\
6-18 \\
>18\end{array}$ & $\begin{array}{r}27 \\
137 \\
321\end{array}$ & $\begin{array}{l}10.15 \\
27.22 \\
24.42\end{array}$ & $\begin{array}{l}0.2-64.2 \\
0.0-962.4 \\
0.2-1778.0\end{array}$ \\
\hline $\begin{array}{l}\text { Nonquarantined farm } \\
\text { exposure }\end{array}$ & 299 & $152 / 147$ & $\begin{array}{l}0-5 \\
6-18 \\
>18\end{array}$ & $\begin{array}{r}18 \\
104 \\
177\end{array}$ & $\begin{array}{l}6.42 \\
3.25 \\
3.03\end{array}$ & $\begin{array}{l}0.2-37.4 \\
0.0-42.6 \\
0.0-94.0\end{array}$ \\
\hline $\begin{array}{l}\text { Michigan Chemical } \\
\text { Company workers }\end{array}$ & 53 & $53 / 0$ & $\begin{array}{r}0-5 \\
6-18 \\
802)\end{array}$ & $\begin{array}{r}0 \\
0 \\
53\end{array}$ & $\overline{-}$ & $\begin{array}{c}- \\
1.0-\overline{1000.0}\end{array}$ \\
\hline $\begin{array}{l}\text { Marshfield, Wisconsin, } \\
\text { dairy farmers }\end{array}$ & 228 & $126 / 102$ & $\begin{array}{l}0-5 \\
6-18 \\
>18\end{array}$ & $\begin{array}{r}10 \\
69 \\
149\end{array}$ & \multicolumn{2}{|c|}{$\begin{array}{l}\text { PBB nondetectable in } \\
222 / 228 \text { samples }\end{array}$} \\
\hline
\end{tabular}

"In parts per billion.

Michigan Chemical workers comprised those individuals employed by the Michigan Chemical Company who were directly involved in the manufacturing and processing of PBBs, or were otherwise employed in the plant. Only volunteers of the work force were examined.

In addition, when dairy farmers volunteered for examination, they were asked about others who had purchased food directly from their farms. These people were then also invited to participate, giving us additional categories of "consumers" from quarantined and nonquarantined farms.

The number of individuals in each of these groups and their sex and age distribution are outlined in Table 2. Residents of quarantined farms were postulated to be a high-exposure group whose route of exposure was primarily by ingestion, with some possible exposure by contact. Residents of nonquarantined farms were postulated to be a moderate-to-low-exposure group whose route of exposure was also primarily by ingestion and some contact exposure. Consumers of products directly from quarantined and nonquarantined farms are categorized together with the farmers from whom they purchased food; their exposure would have been virtually entirely by ingestion. Michigan Chemical Company workers were postulated to be a high-exposure group whose route of exposure was largely by inhalation and contact.

Definition of control group. The control group consisted of members of farm families residing in the Marshfield, Wisconsin, area who were drawn as a random, stratified sample from a list of dairy farmers in the area and invited to participate in the study; they had no history of exposure to polybrominated biphenyls. Again, all who participated were volunteers. Their number and sex and age distribution are also listed in Table 2.

In addition to the study subjects defined above, other exposed individuals were 
also examined. The results are not included in our data since those examined were self-selected or referred by physicians and others, and not derived from defined populations. Even for those invited in our stratified samples of farm lists provided by the Michigan Department of Agriculture, one cannot exclude some bias of self-selection inherent in examining volunteers.

Study design. All members of the study and control group completed identical examinations and were studied in similar facilities under like climatic conditions. The history comprised an extensive but simple cutaneous questionnaire listing any and all cutaneous problems which developed during the period of the spring of 1973 to the fall of 1976 . Each questionnaire was individually reviewed by one of us (J.J.C. or R.W.G.). Almost all of the study group had serum samples drawn and analyzed for serum PBB concentration. Random members of the control group also had serum samples drawn and analyzed for serum PBB concentration. These analyses were performed by the Environmental Sciences Laboratory of the Mount Sinai School of Medicine of the City University of New York (17).

Analysis of data. Prevalence of cutaneous symptoms and signs in exposed individuals were determined and then compared to those observed in controls for statistical significance, using the $\chi^{2}$ test and Fischer's Exact Test where indicated. Prior to evaluating our results it was determined that statistical significance would be assigned according to the following $P$ values: $P<0.001-$ high significance: $P<$ 0.01 -strong significance; $P<0.05$-moderate significance; $P<0$. 1 -suggestive significance (18).

\section{RESULTS}

Results were divided into two categories: subjective findings or symptoms of which subjects complained, and objective findings or signs which were detected on physical examination. All significant positive findings occurred with one exception in adults. In most instances three separate significant levels for each symptom and sign were determined: (1) quarantined and nonquarantined farm residents and consumers considered as a group and compared to controls $(Q+N Q$ vs C); (2) quarantined farm residents considered as a group and compared to controls ( $Q$ vs $C$ ); and (3) nonquarantined farm residents and consumers considered as a group and compared to controls (NQ vs C). In the single instance where an abnormal finding occurred with increased incidence in the Michigan Chemical Company workers, the Michigan Chemical subjects only were compared to the control group. Serum PBB values are presented for each group (Table 2). Symptoms noted with corresponding $P$ values are summarized in Tables 3 and 4 and observed objective findings are shown in Table 5.

\section{Subjective Findings in Self-Administered Questionnaire}

Thirty-two percent of adult residents and consumers associated with quarantined and nonquarantined farms complained of the development of unexplained cutaneous itching in a 3-year period from the PBB contamination episode to the time of the examination, as compared with $22 \%$ reported by the control group ( $P$ $<0.025)$. There was also a higher proportion of dryness reported; $32 \%$ of the 
TABLE 3

SKIN Symptomatology among INDIVIduAls ExpOSED to PBBs (ADULTS)

\begin{tabular}{|c|c|c|c|c|}
\hline \multirow{2}{*}{$\frac{\text { Symptom }}{\text { Peeling and scaling }}$} & \multicolumn{2}{|c|}{ Group $(n)$} & \multirow{2}{*}{$\frac{\begin{array}{c}\text { Prevalence } \\
(c)\end{array}}{17}$} & \multirow{2}{*}{$\frac{P \text { value }}{<0.025}$} \\
\hline & $\mathrm{Q}+\mathrm{NQ}$ & $(498)$ & & \\
\hline & $\mathrm{Q}$ & (321) & 17 & $<0.025$ \\
\hline & $\mathrm{NQ}$ & $(177)$ & 18 & $<0.025$ \\
\hline & $\mathrm{C}$ & (149) & 9 & - \\
\hline \multirow[t]{4}{*}{ Erythema } & $\mathrm{Q}+\mathrm{NQ}$ & (498) & 12 & $<0.025$ \\
\hline & $\mathrm{Q}$ & (321) & 11 & $<0.05$ \\
\hline & NQ & (177) & 13 & $<0.01$ \\
\hline & $\mathrm{C}$ & (149) & 5 & - \\
\hline \multirow[t]{4}{*}{ Hair loss } & $\mathrm{Q}+\mathrm{NQ}$ & $(498)$ & 12 & $<0.025$ \\
\hline & $\mathrm{Q}$ & (321) & 13 & $<0.025$ \\
\hline & NQ & $(177)$ & 11 & $=0.06$ \\
\hline & $\mathrm{C}$ & (149) & 5 & - \\
\hline \multirow[t]{4}{*}{ Increased nail growth } & $\mathrm{Q}+\mathrm{NQ}$ & $(498)$ & 8 & $<0.01$ \\
\hline & $\mathrm{Q}$ & (321) & 7 & $<0.01$ \\
\hline & $\mathrm{NQ}$ & $(177)$ & 11 & $<0.01$ \\
\hline & $\mathrm{C}^{-}$ & (149) & 0 & - \\
\hline \multirow[t]{4}{*}{ Increased sweating } & $Q+N Q$ & $(498)$ & 22 & $=0.025$ \\
\hline & $\mathrm{Q}$ & (321) & 21 & $=0.06$ \\
\hline & NQ & (177) & 24 & $<0.025$ \\
\hline & $\mathrm{C}$ & (149) & 13 & - \\
\hline \multirow[t]{4}{*}{ Itching } & $\mathrm{Q}+\mathrm{NQ}$ & (498) & 32 & $<0.025$ \\
\hline & $\mathrm{Q}$ & (321) & 31 & $=0.06$ \\
\hline & NQ & (177) & 32 & $=0.02$ \\
\hline & $\mathrm{C}$ & (149) & 22 & $-\cdots$ \\
\hline \multirow[t]{4}{*}{ Dryness } & $\mathrm{Q}+\mathrm{NQ}$ & $(498)$ & 32 & $=0.08$ \\
\hline & $Q$ & (321) & 33 & $=0.06$ \\
\hline & $\mathrm{NQ}$ & $(177)$ & 30 & $=0.1$ \\
\hline & $\mathrm{C}$ & (149) & 24 & $\sim$ \\
\hline
\end{tabular}

Note. $\mathrm{Q}=$ Quarantined farm, NQ - nonquarantined farm. $\mathrm{C}$ - controls.

" $\chi^{2}$ test, Fischer's Exact Test.

quarantined and nonquarantined farm adults compared to $24 \%$ of the control group $(P=0.08)$. Similarly, $17 \%$ of the farm study groups complained of the development of unexplained peeling and scaling during the same period compared with an incidence of $9 \%$ in the control group $(P<0.025)$. The prevalence of erythema in the combined farm study groups was $12 \%$ compared with a prevalence of $5 \%$ in the control $(P<0.025)$. Increased unexplained nail growth was reported by $8 \%$ of the quarantined and nonquarantined adults compared with none in the controls $(P<0.01)$. Increased abnormal sweating was a complaint of $22 \%$ of the quarantined and nonquarantined group compared with $13 \%$ in the controls ( $P$ $=0.025$ ). Unexplained hair loss was a complaint of $12 \%$ of the quarantined and nonquarantined group compared with $5 \%$ in the control group $(P=0.025)$ (Table 3). 
TABLE 4

Prevalence of Physician-Elicited Symptoms by Exposure Group

\begin{tabular}{lcccccc} 
Study group & $\begin{array}{c}\text { Total } \\
\text { examined }\end{array}$ & $\begin{array}{c}\text { Current or past } \\
\text { skin complaints } \\
(\%)\end{array}$ & \multicolumn{3}{c}{ Serum PBB" } \\
\cline { 5 - 7 } \multicolumn{1}{c}{ Mean } & Range & $n$ \\
\hline Plant PBB department & 10 & 70 & 603.9 & $11.4-1729$ & 10 \\
Other plant departments & 45 & 31 & 16.5 & $4-234$ & 45 \\
Quarantined farm residents & 359 & 30 & 24.4 & 0.2 & 1778 & 321 \\
Nonquarantined farm residents & 199 & 33 & 3.0 & $0-94$ & 177 \\
Wisconsin farm residents & 153 & 18 & $-{ }^{\prime \prime}$ & - & 149 \\
\hline
\end{tabular}

Note. All exposed groups had significantly higher prevalence of skin symptoms than the comparison group, $P<0.05$.

"Parts per billion ( $\mathrm{ng} / \mathrm{ml})$.

"PBB nondetectable.

\section{Subjective Findings (Physician Interview)}

At the time of physical examination, a review of symptoms was undertaken. Table 4 summarizes prevalence of any dermatologic symptoms experienced over the 3 years prior to examination. All exposed groups had a significantly increased prevalence compared to the comparison group. Although the numbers were small,

TABLE 5

Objective Findings: Skin Changes among Individuals Exposed to PBB (Adults)

\begin{tabular}{|c|c|c|c|c|}
\hline Objective findings & \multicolumn{2}{|c|}{ Group $(n)$} & $\begin{array}{c}\text { Prevalence } \\
(\%)\end{array}$ & $P$ value ${ }^{\prime}$ \\
\hline \multirow[t]{4}{*}{ Diffuse alopecia } & $Q+N Q$ & (498) & 4 & $<0.005$ \\
\hline & $\mathrm{Q}$ & (321) & 5 & $<0.005$ \\
\hline & NQ & (177) & 2 & $=0.08$ \\
\hline & $\mathrm{C}$ & (149) & 0 & - \\
\hline \multirow[t]{5}{*}{ Halogen acne } & $\mathrm{Q}+\mathrm{NQ}$ & (498) & 3 & $>0.1$ \\
\hline & $\mathrm{Q}$ & $(321)$ & 2 & $>0.1$ \\
\hline & NQ & (177) & 5 & $<0.05$ \\
\hline & $\mathrm{MC}$ & (53) & 13 & $<0.001$ \\
\hline & $\mathrm{C}$ & $(149)$ & 0 & - \\
\hline \multirow[t]{4}{*}{ Folliculitis } & $Q+N Q$ & (498) & 23 & $>0.1$ \\
\hline & $\mathrm{Q}$ & $(321)$ & 23 & $>0.1$ \\
\hline & NQ & $(177)$ & 24 & $>0.1$ \\
\hline & C & (149) & 30 & - \\
\hline \multirow{4}{*}{$\begin{array}{l}\text { Irritant or allergic } \\
\text { contact dermatitis }\end{array}$} & $\mathrm{Q}+\mathrm{NQ}$ & (498) & 3 & $>0.1$ \\
\hline & $Q$ & $(321)$ & 3 & $>0.1$ \\
\hline & NQ & (177) & 3 & $>0.1$ \\
\hline & $\mathrm{C}$ & (149) & 9 & - \\
\hline
\end{tabular}

Note. $\mathrm{Q}=$ Quarantined farm. $\mathrm{NQ}=$ nonquarantined farm, $\mathrm{MC}=$ Michigan Chemical Company worker, $\mathrm{C}=$ controls.

" $\chi^{2}$ test, Fischer's Exact Test. 
the PBB production department chemical workers reported the most skin complaints and had the highest serum PBB levels. The production workers had a significantly higher prevalence than the other three groups studied $(P<0.05$ for all three). The two farm groups and the nonproduction chemical workers had similar prevalences of skin complaints.

Of the symptoms elicited, rash was the most frequent reported. Among the farmers, rash was reported by $14 \%$ compared to $9 \%$ in the Wisconsin farm group. Symptoms were elicited for each year from 1971 to the time of examination. This information was used to investigate the time dynamics of symptom appearance. It was possible to evaluate a "retrospective" incidence by year. Rash was typical of the symptoms which had a high enough frequency to allow incidence evaluation. The incidence of rash gradually increased until 1975 and then decreased in 1976 almost to the preepisode level (16).

\section{Objective Findings (Determined by Examination)}

Diffuse unexplained alopecia was observed in $4 \%$ of the combined quarantined and nonquarantined farm group, compared to none in controls, for a $P$ value of less than 0.005 (Table 5). Halogen acne was observed on physical examination in $13 \%$ of Michigan Chemical workers compared to none in controls $(P<0.001)$. Halogen acne was also observed in $3 \%$ of the combined quarantined and nonquarantined farm groups. This, however, was not of statistical significance, as defined by us, when compared to controls $(P>0.1)$. Folliculitis and irritant or allergic contact dermatitis were observed in the combined quarantined and nonquarantined farm group but not with increased frequency when compared to controls.

\section{Serum PBB Levels}

A detailed discussion of the laboratory methods and test results can be found elsewhere (17). Serum PBB levels were measured in $96 \%$ of the dermatologic study groups and in all controls. Description of the serum PBB levels (pbb) by study and age group appears in Table 2. The mean serum PBB levels are consistent with the postulate that, in general, residents and consumers of quarantined farms probably had higher exposure than residents and consumers of nonquarantined farms, and Michigan Chemical Company PBB production workers had the highest exposure. Serum PBB levels in chemical workers in nonproductive jobs had levels similar to those in quarantined farmers. PBB levels were not detectable in 222 of 228 randomly selected control samples; in the six, history of having lived in Michigan during the contamination episode was available.

\section{DISCUSSION}

On the basis of the findings it is reasonable to conclude that polybrominated biphenyls probably have significant cutaneous toxicity. We recognize that this conclusion must be viewed within the framework of a study conducted more than 3 years after the initial exposure episode and involving an agent for which absorption, metabolism, and toxicity data in humans are limited. Nonetheless, our findings are consistent with an influence of polybrominated biphenyls for cutaneous 
toxicity. This conclusion is suported by the observations of similar cutaneous abnormalities in PBB-contaminated animals $(2,4,19)$, and by similar cutaneous abnormalities in PCB-contaminated animals and humans exposed to PCBs (9-14).

There are several questions. It is unclear why cutaneous symptoms and signs appeared almost exclusively in adults, as opposed to children, when serum PBB values of presumably significant levels were obscrved in both group. Recent experimental studies have suggested that certain minor $\mathrm{PBB}$ components produce a more intense skin reaction (rabbit) than the major PBB component which is used to calculate serum PBB levels (20). This may explain the discrepancy. Alternatively it may be that PBBs are metabolized, stored, or excreted differently in children than adults, or that for some unknown reason children are less suscentible to toxic cutaneous effects than adults.

It is also unclear from this study why the Michigan Chemical workers, in whom the highest mean serum PBB levels were observed, were almost uniformly spared any cutaneous toxicity with the exception of acne. Presumably this is related to the route of exposure of these individuals, which was primarily inhalational and by contact, whereas the primary route of exposure in the quarantined and nonquarantined farm groups was by ingestion. Because of many potential exposures to chemical irritants in the plant, the high prevalence of skin symptoms by history may have been expected and cannot by wholly attributed to PBB exposure.

The different prevalence of symptoms and signs in quarantined and nonquarantined farm groups, which did not necessarily correspond to our postulated exposure classification (quarantined: nonquarantined) of these groups (that is, higher incidence of peeling and scaling, erythema, increased nail growth, abnormal sweating, itching, halogen acne in our nonquarantined or moderate-low-exposure group when compared to our quarantined or high-exposure group), was of interest. This observation may reflect the fact that these groups are not homogeneous high- and low-exposure groups and perhaps should not be considered as such, but should rather be considered simply as exposed groups. It seems reasonable to assume that residents of both quarantined and nonquarantined farms had varying intensity and duration of $\mathrm{PBB}$ exposure, reflecting the actual eating preferences rather than the Department of Agriculture's administrative categories. It is for this reason that these groups were compared to the control group both individually and combined. Also, the wide individual variation in response to skin irritants, recognized in other circumstances, may also be a confounding factor.

The symptoms and signs observed in exposed individuals were similar for the most part to those observed in the Yusho patients, in PBB-contaminated animals, and in experimentally PCB-exposed animals. Halogen acne is particularly common following PCB exposure $(9,10)$, both by contact and by ingestion, and it was not surprising to observe it in the study group. For purposes of this study halogen acne was defined as a predominantly comedo acne, occurring in an atypical location for acne, in an unusual age group, and related to exposure to PBBs (21). All subjects with halogen acne fulfilled this definition. It was of interest that the prevalence of PBB acne was higher in Michigan Chemical Company workers than in the quarantined and nonquarantined farm groups. This may be a function of increased exposure by contact in the chemical workers as opposed to the ingesta- 
tion exposure of the farmers. Further, halogen acne is known to follow exposure to PCDFs, chlorinated naphthalenes, and similar compounds contaminating PCBs. It is possible that analagous contamination in PBB or in the variety of other chemicals present at the chemical plant may be responsible for halogen acne among workers.

The increased prevalence in exposed farmers of peeling and scaling, erythema, itching, and marginally increased incidence of dryness may suggest a role of PBBs as primary cutaneous irritants or sensitizers. It is impossible to determine this from the data, and evidence from human skin testing is unavailable and unlikely to be forthcoming. If PBBs are irritants or sensitizers it is again puzzling why the Michigan Chemical workers werre unaffected. Again this may reflect different responses to different routes of exposure or the fact that Michigan Chemical workers may simply have been more attentive to avoiding prolonged skin contact to a chemical agent, whereas farmers were unaware that they were being exposed to a chemical agent at all, and therefore took no measures to avoid prolonged skin contact.

The observed alopecias were diffuse and nonscarring as were those described historically. The sweating abnormalities were invariably described as increased sweating under unusual circumstances. The increased fingernail and toenail growth was especially interesting. Affected individuals reported that the frequency required to trim fingernails and toenails had increased from every few months to every few weeks. This was an interesting parallel to the marked hyperkeratotic proliferation of the hooves observed in some PBB-contaminated dairy animals. In addition, nail dystrophy was a reported symptom in the Yusho subjects.

Because of the fact that cutaneous pigmentary changes were frequently observed in the Yusho patients, as was increased prominence of hair follicles (questionable chronic folliculitis), these signs were carefully searched for on physical examination. They were not observed. In addition, since it is known that ingestion of chlorinated naphthalenes can lead to an acquired porphyria, symptoms of increased sun sensitivity, skin blistering, and scarring were carefully sought but were not reported. Finally, increased incidence of acute irritant and/or allergic dermatitis were not observed on examination. This may have been due to the 3-year period between the initial exposure and the subsequent examination.

The mechanism of the cutaneous toxicity of PBBs remains unknown. The observed increased rate of nail growth, increased sweating, increased peeling and scaling, and halogen acne (increased proliferation of follicular infundibular cells), as well as the fact that PCBs and PBBs cause induction of hepatic microsomal enzymes $(5,12)$ and increased liver weight in laboratory animals, suggest that PBBs may somehow stimulate cellular metabolism. Whether this is in fact the case requires investigation by controlled laboratory studies.

\section{CONCLUSIONS}

Within the framework of this study, the following conclusions with regard to the cutaneous toxicity of PEBs are offered: 
(1) PBBs appear to be probable etiological agents for increased nail growth, increased sweating, alopecia, halogen acne, skin dryness, skin erythema, skin peeling and scaling, and pruritus in exposed individuals.

(2) Symptoms and signs are similar to those reported in PCB and PBB animal toxicity studies, and in the Yusho PCB incident in Japan in 1968.

(3) The mechanism of cutaneous toxicity of PBBs is unknown. Observed symptoms and signs suggest that increased cellular metabolism may be a factor.

\section{REFERENCES}

1. Kay, K. (1977). Polybrominated biphenyls (PBB) environmental contamination in Michigan. 1973-1976. Enirun. Res. 13, 74-93.

2. Jackson, F., and Halbert. F. L. (1974). Toxic syndrome associated with the finding of polybrominated biphenyl contaminated protein concentrate to dairy cattle. J. Amer. Vet. Med. Assoc. 164, $437-439$.

3. Humphrey, H. E. B., and Hayner, N. S. (1975). “'Trace Substances in Environmental Health, IX," p. 57. University of Missouri, Columbia.

4. Hass, J. R., McConnell, E. E., and Harvan, D. J. (1978). Chemical and toxicologic evaluation of Firemaster PB-6.J. Agr. Food Chem. 26, 94-99.

5. Dent, J. G., Netter, K. J., and Gibson. J. E. (1976). Effects of chronic administration of polybrominated biphenyls on parameters associated with hepatic drug metabolism. Res. Commum. Pathol. Pharmacol. 13, 75-82.

6. Sleight, S. D., and Sanger, V. L. (1976). Pathologic features of polybrominated biphenyl toxicosis in the rat and guinea pig. $J$. Amer. Vet. Mod. Assoc. 196, 1231-1235.

7. Norris. J. M., Kociba, R. J., Schwetz. B. A. et al. (1975). Toxicology of octabromobiphenyl and decabromodiphenyl oxide. Environ. Health Perspect. 11, 153-161.

8. Norris, J. M., Ehrhamtraut, J. W., Gibbons, C. L., at (1974). Toxicological and envirnnmental factors involved in the selection of decabromodiphenyl oxide as a fire retardant chemical. In "KFF/Combustion Toxicology," Vol. 1, Feb. 1974. Presented paper at Conference on Polymer Materials for Unusual Service Conditions. Ames Research Center. National Aeronautics and Space Administration, Moffett Field, California, Nov. 1972.

9. Kimbrough, R. D. (1972). Toxicity of chlorinated hydrocarbons and related compounds. Arch Enitum. Health 25, 125-131.

10. Fischbein, L. (1974). Toxicity of chlorinated biphenyls. In "Annual Review of Pharmacology" (H. W. Elliot et al.. Eds.), Vol. 14. pp. 139-156. Annual Reviews. Palo Alto, Calif.

11. Allen, J. R. (1975). Response of the nonhuman primate to polychlorinated biphenyl exposure. Fed. Proc. 34, 1675-1679.

12. Allen, J. R.. Carstens, L. A.. Abrahamson, L. J., et al. (1975). Responses of rats and nonhuman primates to 2,5,2',5'-tetrachlorobiphenyl. Emiron. Res. 9, 265-273.

13. Allen, J. R., Carstens, L. A., and Barsotti, D. A. (1974). Residual effects of short-term, low-level exposure of non-human primates to polychlorinated biphenyls. Toxic. Appl. Pharmacol. 30, $440-451$.

14. Okermura, M., and Katsuki, S. (1969). Clinical observations on "Yusho." Fukuoka Acta Med. 60, $440-446$.

15. Karatsune, M., Masuda, Y., and Nagayama, J. (1976). Some of the recent findings concerning Yusho. In "Proceedings National Conference on Polychlorinated Biphenyls, November 1975," pp. 14-19. Environmental Protection Agency. Chicago.

16. Anderson. H. A., Wolff, M. S. Lilis, e't al. (1900). Symptoms and clinical abnormalities following ingestion of polybrominated-biphenyl-contaminated food products. Ann. N.Y. Ac'ad. Sci. 320, $684-702$.

17. Wolff, M. S., Anderson, H. A., Camper, F., Nikaido, M. N., Daum, S. M., Haymes, N., Selikoff, I. J., and Aubrey, B. (1979). Analysis of adipose tissue and serum from PBB-exposed workers. J. Environ. Pathol. Toxicol. 2, 1397-1411. 
18. Burdette, W. J., and Gehan, E. A. (1970). "Planning and Analysis of Clinical Studies." Charles C Thomas, Springfield, Ill

19. Kimbrough, R. D., Buse, V. W., and Liddle, J. A. (1977). Toxicity of polybrominated biphenyl, FF1 in rats and rabbits: Persistence, hepatic porphyria. Lanc't $602-603$.

20. Paterson, D. G., Hill, R. H., Needham, L. L., Orti, D. L., Kimbrough, R. D., and Liddle, J. A. (1981). Hyperkeratosis induced by sunlight degradation products of the major polybrominated biphenyl in Firemaster. Science 213, 901-902.

21. Cunliffe, W. J., and Cotterill, J. A. (1975). "The Acnes: Major Problems in Dermatology." Saunders, Philadelphia. 